\title{
Push or be punished: tobacco industry documents reveal aggression against businesses that discourage tobacco use
}

\begin{abstract}
Objective-To learn how the tobacco industry reacted to businesses' voluntarily enacting policies to discourage tobacco use and minimise exposure of employees and patrons to secondhand smoke.

Data sources-Internal tobacco industry documents discovered among those posted on the internet. Approximately 24 million documents have been posted as of this writing. Information in this article was culled from among these documents, which have been made public as a unique requirement of the state of Minnesota's settlement with the industry.

Study selection-Those documents were used that offered insight into, and which gave a perspective on, the industry's attitudes and reactions toward other businesses as they adopted tobacco-free policies.

Conclusions-In the wake of widespread acceptance that tobacco use causes illness and death, many individual businesses (and even entire industries) took positive steps to eliminate employees', customers', and facilities' exposure to tobacco smoke. Steps were also taken to discourage tobacco use among employees. Internal tobacco industry documents show that the industry reacted with aggression, and in some cases with retribution, against businesses that voluntarily adopted policies to discourage tobacco use. The intent of these actions appears to be to reverse these policies, with a broader goal of neutralising large scale public and private trends that reflect the decreasing social acceptability of tobacco use.

(Tobacco Control 2000;9:339-346)
\end{abstract}

Keywords: tobacco industry; tobacco-free policies; aggression

Since the summer of 1998, approximately 24 million internal tobacco industry documents have been placed onto the world wide web, where the public has unlimited freedom to view them. Placing these documents in the public realm was a requirement of the Master Settlement Agreement between 42 US states and the tobacco industry, and was also part of the settlement between the state of Minnesota and the tobacco industry. The release of such a large cache of internal corporate documents is unprecedented in history. Though the indices to these documents are poor, with patience and time spent learning to use them, one can gain significant insight into this industry's inner workings.

The public's picture of the tobacco industry has historically been superficial, since it has been shaped by the industry itself either through paid media buys or newspaper articles that discuss the progress of a damage or injury trial. The industry has only let the outside world see it as it wants to be seen, showing only a finely tuned image crafted by top public relations professionals.

Public exposure of the industry's internal documents has changed all this. For the first time, the public has access to a wide range of information describing tobacco industry behaviour-information that was previously inaccessible to those outside the industry. The documents give investigators unprecedented insight into this powerful and increasingly desperate industry. Now that the documents are public, the world has an historic opportunity to peel back the armour of this previously impenetrable industry, peer inside and see how it behaved in the face of increasing acceptance of the evidence that its products harm and kill.

This article uses information revealed in the documents to briefly explore the attitudes and actions of the tobacco industry toward other businesses that acted upon the knowledge that tobacco causes harm.

The tobacco industry: fuming over the decreasing social acceptance of tobacco use

Overwhelming information about the physical harm caused by tobacco use, and increasing knowledge of the ill effects of sidestream smoke, have started a slow but inexorable movement away from what was once a blind acceptance of tobacco use as a norm in the USA. We see these same cultural changes reflected in business policies as well. Many business owners have begun to recognise that tobacco use causes economic and productivity burdens on their businesses. As a result, within the past decade and a half, many businesses have adopted pro-health policies: offering smoking cessation programmes to employees, bonuses for employees who successfully quit smoking, and enacting clean indoor air policies to protect workers, patrons, and capital interests. Pharmaceutical companies began developing and marketing smoking cessation aids, smoking was banned on public conveyances, insurance companies started 
offering different rates to non-smoking policy holders. Such policies gradually spread throughout the public and private business sector in the USA.

Documents reveal that the tobacco industry did not take these changes lightly, and often did not stop at simply being angry about the changes. Many businesses that enacted pro-health policies became targets of tobacco industry aggression. This aggression took many forms: threatening letters, economic attacks or threats thereof, orchestration of congressional investigations, and the formation of "front groups" to stir up public sentiment against businesses, to name a few. Evidence of these behaviours can be found in an assortment of document types, from tobacco executives' brief, hand written notes on scratch pads to formal reports that describe well organised, extensively funded campaigns against other industries. Because most of the tobacco industry's aggression against other businesses took place on a "corporation to corporation" level, however, the public took little note of its occurrence.

This article will discuss some findings among the industry's internal documents that reveal hostile attitudes and aggressive actions by the tobacco industry against businesses enacting pro-health policies.

\section{Corporate retaliation}

MERRELL DOW PHARMACEUTICALS

A series of Philip Morris (PM) documents from the early 1980 s reveal PM's anger toward the Merrell Dow/Dow Chemical Company after it began marketing the smoking cessation aid Nicorette.

Dow's vulnerability lay in the fact that it was PM's sole domestic supplier for humectants, the chemicals PM adds to its tobacco to keep it moist.

To advertise Nicorette gum, Dow produced and distributed a publication called The Smoking Cessation Newsletter. PM chemist Thomas S Osdene wrote the following in a confidential PM memo dated January 5, 1982, after a copy of Dow's Smoking Cessation Newsletter came to his attention:

The attached [Dow] Smoking Cessation Newsletter came into my hands from one of our consultants. I checked with Bob Latshaw of the purchasing department to see what our approximate total purchases from Dow Chemical have been over a two year period. The figures are as follows . . . 1980-4.4 million dollars, 1981-5.2 million dollars. For 1982 purchases in the amount of 7.7 million dollars are anticipated. The materials we purchase are largely glycerol, propylene glycol and triethylene glycol. You may wish to lodge some type of a protest.

Philip Morris $1982^{1}$

PM played out its threat. In another memo (dated 7 May 1984), Bob Latshaw of PM's purchasing department writes:
Per our conversations, we ceased issuing glycerine, propylene glycol and triethylene glycol orders to Dow. They requested a meeting to discuss the situation which was held on Wednesday, May 2 ...

Dow was told that we were discontinuing all humectants purchases because of Dow-Merell's attack on cigarette smoking associated with the introduction of Nicorette, a nicotine-containing prescription chewing gum which reportedly aides "patients" in quitting smoking. Specific examples of Dow's objectionable campaign were cited:

1. Efforts to encourage all smokers at their Freeport Plant (source of most of our materials) to give up smoking.

2. The Dow sponsored Policy Analysis Incorporated study indicating an additional $\$ 59000$ lifetime medical expense for smokers.

3. Dow literature appearing in doctors' offices encouraging smokers to quit by using Nicorette.

4. A new Richmond doctor's clinic discouraging smoking and offering

Nicorette ...

Philip Morris $1984^{2}$

Note the exception PM took to the word "patients" in the newsletter, a word that characterises nicotine users as in need of medical help to quit smoking. When nicotine replacement therapy was first marketed, people had to obtain these products by prescription from a physician. It appears that PM ignored or denied this fact. PM also took exception to what it construed as competition on its own turf: marketing of a novel, new nicotine containing product. Another memo indicated that Dow was the only domestic supplier of humectants and that ceasing purchases from Dow was "not without some risk" to PM. ${ }^{3}$ Still, PM decided the risk was worth it, and withdrew purchases of humectants from Dow Chemical as punishment for Dow's encouraging smoking cessation both internally and externally.

\section{FEDERAL EXPRESS}

Correspondence found among the RJ Reynolds (RJR) documents shows that Frederick W Smith, the chief executive officer of Federal Express (a large shipping company), was forced to defend his company's newly established smoke-free policy to the tobacco industry. RJR's chief executive officer, GH Long, apparently reprimanded Smith after Fed Ex enacted a policy eliminating smoking from its offices and facilities in 1987. The original letter from Long to Smith could not be found, but Smith's written response to RJR reflects the content of the original communique from RJR:

\footnotetext{
Dear Mr Long:

I'm truly sorry for the publicity about our smoking policy-we certainly didn't initiate it. I think it's important you understand what "Federal Express" is ...

-About 20000 trucks and 200 transport aircraft, chock full of flammable items wherein smoking is prohibited.
} 
-Many millions of square feet of garages and package sorting facilities where the same restrictions apply.

Our employee relations are outstanding largely because we are very egalitarian. To these ends, since the vast majority of our employees cannot smoke in their "offices", e.g. our planes or trucks or warehouses, we came to the conclusion that we should simply restrict smoking throughout our facilities for our employees.

...We also think that in addition to the safety and employee relations issues, largely unique to FedEx, this policy will help promote better health for our employees.

...We are not trying to engage in any crusade against smoking or tobacco firms, but we do feel compelled to make decisions that we feel are required by our business. I certainly hope with a [sic] understanding of these facts you will continue to look upon Federal Express as a dependable supplier for your firm.

Sincerely,

Frederick W. Smith

[emphasis added]

Rf Reynolds $1987^{4}$

The assumption can be made from this letter that RJR's long threatened to withhold RJR-Nabisco's shipping business from Fed Ex to punish it for its decision to go smoke-free. This is another example of a tobacco company using its economic muscle to try and reverse a voluntarily enacted tobacco-free policy in a private business.

\section{Hospitals}

A handwritten confidential note found on the Tobacco Institute site indicates the industry's disdain towards a new policy banning the sale of cigarettes in Veterans Administration (VA) hospitals. The following confidential note, written by Fred Panzer to Jim Mills of the RJR, makes this evident. A newspaper clipping of an article entitled "Veterans Hospital in Chicago bans sale of cigarettes" was transmitted with the note. The note reads:

Fred

In view of Rep. Gross' interest as expressed in the $\mathbf{7 4 8 2}$ debate Monday, he might like to take on the VA cig sales ban movement. Would like to see someone keep the heat on to point up the stupidity of making it more difficult for hospitalized veterans to obtain cigarettes if they choose to smoke.

Jim $9 / 12$

Tobacco Institute $1973^{5}$

Another Tobacco Institute memo indicates the industry's intent to begin a full fledged campaign to discourage American hospitals from developing smoke-free policies. A 1991 memo to Sam Chilcote, president of the Tobacco Institute, from his public affairs assistant Susan Stuntz reveals this:

Attached for your review are copies of programs for two components of our expanded public smoking/workplace effort. The first addresses efforts to discourage health insurers from discriminating against smokers and relies largely on allies and outside consultants to accomplish our goals.
The second program is designed to encourage restaurant owners to adopt voluntary policies that accommodate smokers and nonsmokers . .., . . A third program aimed at discouraging American Hospital Association from launching a nationwide public relations campaign encouraging smoking bans in hospitals is undergoing legal review. [Emphasis added]

Tobacco Institute $1991^{6}$

Relying on outside consultants to achieve stated goals implies that Tobacco Institute executives understood the damage that would result if the public discovered the Institute was behind these programmes, and thus recognised the need to have others to carry their message.

\section{Public conveyances}

MASSACHUSETTS BAY TRANSPORTATION AUTHORITY

When the board of the Massachusetts Bay Transportation Authority (MBTA) voted to stop accepting tobacco advertisements for its vehicles and in its facilities in 1986, the Tobacco Institute devised a comprehensive plan to reverse MBTA's decision. The executives of the Tobacco Institute knew that the industry was unable to openly fight MBTA's move, and once again engaged in using third parties to carry out its aggressive tactics. The Institute's plans included inciting advertising companies that had lost out in MBTA's bidding process to sue MBTA, charging that the transit authority's system of awarding contracts was discriminatory. A memo also indicates the Institute approached its allies, the American Civil Liberties Union (ACLU) and labour unions, to enlist more help in its battle against MBTA.

A lengthy memorandum from the Tobacco Institute describes a programme to stir up public sentiment against MBTA over the new tobacco-free policy, and to ultimately get MTBA to reverse it. The memo begins,

This memorandum will bring you up-to-date on the status of our program to reverse the action of the Massachusetts Bay Transportation Authority (MBTA) to ban cigarette advertising from the system's vehicles and facilities.

Short-range plans for MBTA were laid out:

...Our immediate interest is the extension of the time available to the industry to continue to implement legislative and other programs. The best available means of extending that time seems to be through the legal intervention of a third party-one of the [advertising] contract bidders or Local \#391 . . .who ultimately obtains a preliminary injunction ... is irrelevant. The current issue is that someone obtain that order...

and,

...Our plan here is to continue to generate negative political response to the MBTA action in the cities and towns served by the MBTA.

Tobacco Institute 1986 
The Tobacco Institute also used the (US) Freedom of Information Act (FOIA) to force MBTA to supply it with copies of paperwork that had anything to do with its contract award system. The use of public records acts to interfere with tobacco control efforts is recognised by US tobacco control advocates as a tactic commonly employed by the industry to undermine public health actions. Abuse of public records laws was the subject of a previous article in Tobacco Control, ${ }^{8}$ which described the tactic. Demanding copies of hundreds, even thousands of documents under the FOIA laws increases burdens upon an "offending" organisation by sidetracking workers, diminishing productivity towards its mission, and creating financial hardship by increasing their expenses and operating burdens.

A boastful 1988 report by Roger Mozingo of the Tobacco Institute about the Institute's track record of stopping public health measures across the country reveals the Institute's diabolical and ingenious "white hat proposal" against MBTA. This plan was to insert an amendment into the state budget to eliminate MBTA's authority to restrict the types of advertising it could accept in the future (thus forcing it to accept tobacco advertising):

We have offered a measure that requires the MBTA to maximize advertising revenue from all legal sources and channel those funds to help the elderly and handicapped. This "white hat" proposal would supersede the ban on tobacco advertising and, in theory at least, require the MBTA to use all legal sources for this worthwhile project . . .[handwritten] . . .including tobacco advertising.

1988, Tobacco Institute

The Tobacco Institute's fall back plan was to use their political influence to cut MBTA's federal funding:

It is still possible that the MBTA . . .might respond to pressure from federal office holders who participate in the Congressional committees that have control over some forms of transit funding. These include the House Committee on Public Works and Transportation, the Senate Committee on Commerce, Science and Transportation, the House Committee on Appropriations and the Senate Committee on Appropriations.

Tobacco Institute 1986

Interfering with the transit authority's federal funding going to appears to be a purely punitive action that was to be pursued if and when other tactics to get MBTA to reverse its decision failed.

\section{Airlines}

Airlines also felt the wrath of tobacco companies after they introduced smoking and non-smoking sections on their flights. The industry's wrath escalated after smoking was banned from US flights altogether.
Eastern Airlines introduced no-smoking sections on its flights in 1977. At this time, they merely grouped smokers together in one part of the airplane to try and preserve a measure of cleanliness in the air in the rest of the cabin for their non-smoking passengers. Upon that move, Horace Kornegay, then the president of the Tobacco Institute, issued this nearly hysterical message:

\section{AN URGENT MESSAGE}

Eastern Airlines has entered an unconscionable agreement with Prohibitionist "consumer groups" to squeeze travelers who enjoy tobacco into the rear third of its flight cabins. The agreement was reached privately in spite of its implications of potential second class citizenship for 55 million Americans. As of today, it's on file at the US civil Aeronautics Board where the airline and the anti-tobacco activists are pushing for its approval.

Lorillard $1977^{10}$

The notice urges recipients to call government officials and protest Eastern Airline's move.

The Lorillard Tobacco Company also took aim at Air Canada after it became the first North American airline to introduce completely non-smoking flights. Lorillard employed its economic clout to punish Air Canada. Lorillard sent a memo to all of its vice presidents, division heads, plant managers, and regional sales directors announcing that the company was modifying its own internal policy in reaction to American's move:

Air Canada having decided to become the first major North American airline to introduce total non-smoking flights, thus severely restricting the number of its flights available to Canadian smoker, ITL travel policy is modified as follows, effective immediately:

1. where employees travel on company business, Air Canada must be their last choice of airline for such travel. Employees who will use Air Canada services for company travel will be asked to justify their decision at the time they submit their expense account and will be expected to supply evidence that no other reasonable alternative was available for such trips;

2. no expense incurred on company business should be paid by using an En Route credit card and any company expenses so paid after today will not be reimbursed by the company. Lorillard $1986^{11}$

Anti-airline actions by the tobacco companies became more public in 1988 when the RJR reacted against Northwest Airlines' smoking ban

The advertising agency of Saatchi and Saatchi created television ads for Northwest Airlines to advertise Northwest's new policy of providing $100 \%$ smoke-free flights. In one commercial, the camera panned across the passengers in a Norwest cabin, stopping to focus on a solitary smoker. The announcer's voice then proclaimed the smoking ban, and 
the passengers, all at once, burst into applause - all except for the smoker.

Edward Horrigan, then vice chairman of RJR-Nabisco, was enraged to learn that the spot had been created by Saatchi, the agency that was also responsible for most of the advertising for RJR's subsidiary, Nabisco (maker of such popular American cookie products as Oreos and Fig Newtons). Horrigan dispatched two top RJR executives to Saatchi's headquarters to fire the ad company, ending RJR's 18 year relationship with the company. Ultimately RJR pulled $\$ 84$ million worth of advertising from Saatchi as punishment. The ad agency was forced to lay off approximately 120 workers. $^{12}$

\section{Insurance industry}

Of all the examples of tobacco industry aggression towards other companies, none appears to match the ambitious scope of the campaign it carried out against the insurance industry after the advent of non-smoker discounts.

According to the historical perspective of an employee at Met Life Insurance in Elmsford, New York, insurance actuaries first noticed smokers' poorer health, and the greater expense of covering smokers as early as the 1930s. Despite this knowledge, it wasn't until many years later that the insurance industry began offering "non-smoker discounts", which consisted of lower rates for non-smokers (rather than higher rates for smokers). The tobacco industry construed these moves on the part of the insurance industry as enacting "smoker markups" and using "smoker discrimination". In addition, documents indicate the industry viewed incentives rewarding non-smoking behavior as punitive of smokers, and saw these measures as begging for strong and thorough opposition.

Indeed, an attack on the insurance industry was soon in the works. A Tobacco Institute memo reveals that it was preparing a comprehensive plot against the insurance industry as a whole by the end of 1989 :

More and more corporations are voluntarily adopting policies banning or severely restricting smoking in their workplaces. Many employers believe stringent smoking policies will reduce their health care costs, and many insurance companies are fueling this "conventional wisdom" by marketing anti-smoking incentives such as non-smoker discounts on group health insurance policies. Several months ago, I asked Peter Sparber [of Sparber Associates, a Washington DC public relations firm] to assess the prevalence of anti-smoking practices by the insurance industry and to consider ways The Institute might combat them.

[emphasis added]

The public relations company drafting the insurance programme recommended that the tobacco industry organise a "consumer rights" front group to agitate on "the discriminatory nature of smoker discounts", and devised plans to couch this issue in a larger issue of general insurance industry discrimination:

Attached are two memoranda Peter prepared at my request. The first proposes a program to discourage the anti-smoking practices by the insurance industry executives', regulators' and legislators' awareness of the discriminatory nature of non-smoker discounts. John Ingram, once a key "consumer rights" nemesis of the insurance industry, would be the lynchpin of the program. Ingram would create a consumer rights group on behalf of which he would speak and publish to expose the insurance industry's most discriminatory practices.

The second memorandum provides specific details of potential writing and speaking activities and suggests discriminatory practices other than non-smoker discounts that could be the focus of the consumer group's activity.

- . At the same time, the proposal is expensive. Ingram demands no less than $\$ 5000$ per month for six months plus expenses, and Sparber proposes to provide all necessary support of Ingram and his groups for a fixed fee of $\$ 3000$ per month.

Even more telling, however, is a handwritten note to the memo's recipient (Tobacco Institute public affairs employee) Susan Stuntz. The note, which is scrawled on the upper right hand corner of the document by its author Martin Gleason, reads:

Susan-Interesting. Might work if we could wrap smoker discrimination into a package of other credible forms of discrimination. Industry will not take this attack lightly and will fight back fiercely. We would have to have a strong attack and a good defense. MG 11/27 Tobacco Institute $1989^{13}$

By 1991, the Tobacco Institute had given its go-ahead to the project, budgeting $\$ 60000$ to initiate it. Sparber Associates' “Draft Insurance Program" employed the battle tactic of mounting a nationwide "insurance reform" campaign. This ambitious document reveals far reaching plans by the tobacco industry to influence not only American consumer sentiment, but the entire societal perception of the insurance industry through manipulation of politics, legislation, the media, and attitudes of consumer groups. Following is the "Program Summary":

We recommend that the Tobacco Institute identify and support existing critics of the insurance industry to achieve insurance reform that prohibits discrimination against smokers and others.

The program would have three dimensions: 1) Encouraging the use of insurance industry reform as a political issue for federal and state politicians, 
2) Supporting the efforts of consumer groups concerned with insurance reform, with a focus on abolishing discriminatory practices; and

3) Encouraging groups that have been attacked or financially penalized by the insurance industry to respond with the focus on abolishing discriminatory practices.

Tobacco Institute $1990^{13}$

Other passages in Sparber's "Draft Insurance Program" indicate the industry's disdain for workplace smoking cessation programs and wellness clinics:

Following the precedent set by life insurers, the health insurance industry is discriminating against smokers. It charges them higher premium rates and promotes cost containment programs that include smoking cessation clinics and workplace smoking policies ...

...A campaign for insurance reform based on the insurance industry's deceptive practices and its link to medical surveillance of the workforce could end "smoker markups" and reduce the incentive for cost containment "wellness" programs.

Current congressional and consumer group scrutiny of the industry affords a favorable climate for an insurance reform campaign.

Tobacco Institute $1990^{13}$

Broad strategies for the campaign included "reminding" the insurance industry the proper way it was to operate (its "fundamental purpose"), fostering malcontent among legislators, journalists, and consumer groups towards the insurance industry, and then demonstrating that "the industry created the problems" itself:

Strategy I: Support consumer and congressional efforts to force the insurance industry to fulfill its fundamental purpose: to provide protection from loss through pooling risks.

Strategy II: Establish a dual theme of deceptive practices and widespread discrimination in the insurance industry, demonstrating that the industry created the problems that forced business to take discriminatory action against workers-action that violates personal freedom and the right to privacy.

Strategy III: Influence insurance practices through legislators, journalists and consumer groups.

Tobacco Institute $1990^{13}$

The plan lists the politicians and political committees that would be influenced to carry out this campaign, as well as consumer advocates, groups and publications, research organisations, business organisations, labour unions, lawyer associations, and others to be pulled in to assist the campaign. Activities in which they were to engage included drafting position papers on insurance reform, providing insurance reform groups (including, as revealed in the documents, groups of the tobacco industry's own creation) with newsletters, press releases, statements and articles, creating press kits about insurance industry profits (written "in common terms"), sponsoring insurance reform seminars for journalists, legislators, and regulators and even drafting model legislation to be presented to legislators.

Moreover, the information to be compiled and distributed in the above-mentioned written materials was known to be false. Another astonishing memo on the "Insurance Program" states:

...The information we are gathering on the insurance penalties for smokers and others, which are not based on real data, will be the basis for articles and op-eds as appropriate in the coming months.

Tobacco Institute $1991^{14}$

The "Insurance Program" plan was evidence of one of the most far reaching organised programmes by the tobacco industry to attack another industry over its policies.

What is more, according to a Tobacco Institute memo dated October 25, 1991, the plan worked far better than they had anticipated:

Since the approval of the insurance program last year, the complexion of the insurance debate has changed dramatically. Health care and insurance reform are front page news. Varied groups and organizations have demanded changes in the delivery and cost of health care. Our original plan did not anticipate the groundswell of interest in insurance reform ...

Tobacco Institute $1991^{15}$

\section{Discussion}

Until we have completely explored all these documents, we will not know how many more such plans were created and carried out by the tobacco industry, or against which businesses. We will not be able to understand to what extent American citizens have shaped our own destiny, or how much of our destiny was shaped for us by this industry, through its highly orchestrated and pervasive interference in our culture, political processes, consumer sentiment, and media. Perhaps even more disturbing is that unless a similar set of circumstances causes the exposure of internal documents for other powerful and secretive industries, we will never know the extent to which they, too, have directed society to do their bidding.

It is clear that the tobacco industry did not sit idly by while society was taking action upon the knowledge that smoking harms health. Not only did the industry fail in its responsibility to inform the public fully about the hazards of its products, but it transgressed far beyond this, actively threatening and fighting those who were trying to minimise the damage done by its products. It appears that the industry very actively combatted anti-tobacco measures implemented by 
private businesses, through threats, economic retaliation, and through highly orchestrated secret programmes.

This paper presents but a fraction of the documentation of the tobacco industry's acts of aggression and retribution. The industry's actions towards businesses that act on the knowledge that tobacco use is injurious to constitute a serious violation of basic human trust that should not go unnoticed by policymakers and the public.

What also emerges, though, is a clarification of the underlying tactic of how the industry deals with other measures that also threaten its profits. The industry has dealt with the issue of environmental tobacco smoke by broadening the issue into one of "ventilation". This effectively draws attention away from the fact that tobacco smoke is a point source health issue. They used the same tactic in their attack against the insurance industry, broadening the health issue into a larger one (general "insurance discrimination"), thus deflecting attention away from how tobacco use negatively affects the risk pool and increases the financial burden on nonsmokers. In both these cases, the end result is that responsibility is taken off the tobacco industry and put onto others, who in turn endure more expense and confusion about the issue.

This study also points up the contradictions between the industry's public and statements and its private actions. Publicly, the industry claims that it does not promote smoking or discourage any smoker who wants to quit, take any position on quit smoking techniques, campaigns or organisations or on any products or services involved. ${ }^{16}$ This is not borne out in their covert actions, however.

The industry's rhetoric is that "people can quit if they want to", yet it appears determined to make this more difficult than it already is. It has fought the marketing of cessation aids and opposed corporate quit smoking clinics. Stan Glantz and colleagues, in the book about the Brown and Williamson Tobacco Company's internal documents, The Cigarette Papers, noted this contradiction as well. In discussing the tobacco industry's influence on corporations, Glantz colleagues' remark about the concern of Ernest Pepples, Brown and Williamson's chief counsel, about a stop smoking clinic being offered at a private bank:

In view of the industry's consistent public posture that smokers can quit if they so wish, it is hard to understand Pepple's concern over the existence of a stop-smoking clinic at the Chase Bank. ${ }^{17}$

The tobacco industry also publicly advocates an "open-minded debate" on smoking and health issues, but when businesses act upon conclusions reached in that debate, they become subjects of tyrannical opposition by the very industry that claimed to support the informed debate!
The industry promotes "freedom of choice" and "accommodation" in its quest to preserve the social acceptability of smoking. In truth, a business that exercises free choice in its health and safety policies opens itself to the potential for tobacco industry threats, interference, intimidation, and retaliation - the ultimate end of which could mean financial ruin. The tobacco industry's "choice" argument is in practice, then, utterly hollow - to be pulled out and paraded when it is to its advantage and abandoned when it is not.

Yet the industry successfully distances itself from these hypocracies by creating front groups and using third parties to do its bidding, a tactic that effectively buries the truth of its undue influence from the public eye.

Before the release of the documents, few people knew of this desperate industry's iron fisted intimidation tactics towards other businesses. Few, outside the readers of this journal, even know about this now.

Francis Bacon said "Knowledge is power". Understanding this industry's behaviour and strategies will enlighten policy makers, business people, and members of the public (smokers and non-smokers alike), about this industry's egregious acts, and also about the extent to which corporations, through their extraordinary wealth and resources, are able to manipulate societies to suit their own means. My hope is that exposing this information will empower business owners to continue to implement healthy, tobacco-free policies for their employees and the public.

American Lung Association of Colorado

ANNE LANDMAN

Grand Function, Colorado, USA

afoxland@gj.net

1 Osdene TS. "Merrell Dow smoking cessation newsletter", confidential memorandum, 5 January 1982, Philip Morris. www.pmdocs.com, Bates No. 1003481221, downloaded October 1998.

2 Latshaw RD. "Suspension of Dow purchases", memorandum, 7 May 1984. Philip Morris. www.pmdocs.com, Bates No. 2023799799, downloaded October 1998

3 Kay AJ. "Dow Nicorette", memorandum to RE Resnick, 16 December 1985. Philip Morris. www.pmdocs.com, Bates December 1985. Philip Morris. www.

4 Smith FW. Letter to GH Long of RJ Reynolds Tobacco Company, 7 October 1987. RJ Reynolds. www.rjrtdocs.com, Bates No. 506644926 (no download date)

5 Panzer F. Handwritten note to Jim Mills, 12 September 1973. Tobacco Institute. www.tobaccoinstitute.com, Bates No. TIMN 0096583, downloaded 1 June 1999.

6 Stuntz S. Memorandum to Sam Chilcote, 17 May 1991. Tobacco Institute. www.tobaccodocuments.org, Bates No. TI 00003872, downloaded 20 December 1999.

7 Dyer DM. "MBTA proposed ban on cigarette advertising Update \#9", memorandum to William P Buckley, 19 June 191986 . Tobacco Institute. www.tobaccoinstitute.com, Bates No. TIOR0011648/1651, downloaded 18 June 1999.

8 Aguinaga S, Glantz S. The use of public records acts to interfere with tobacco control. Tobacco Control 1995; 4:222-30.

9 Mozingo R. Statement/testimony to the Tobacco Institute, 7 April 1988. Tobacco Institute. http://www. tobaccoinstitute.com, Bates No. TIOK0019080/9094, downloaded $2 / 25 / 00$.

10 Kornegay, HR. "AN URGENT MESSAGE." Letter, 27 June 1977. Tobacco Institute. www.lorillarddocs.com, Bates No. 01254556, downloaded 23 February 1999.

11 Mercer JL. "Re: Air Canada" memo to vice-presidents, division heads, plant managers, regional sales directors, 11 April 1986, Lorillard Tobacco Company, www.lorillarddocs.com, Bates No. 92755868, downloaded 2 February 1999 . 
12 Gibbs N. Getting burned by a ban. Time 18 April 1988 , v131, n16, p64.

13 Lyons J "Re: anti-smoking practices of the insurance industry", memorandum to Susan M Stuntz and Martin J Gleason, November 22, 1989. Tobacco Institute. www.tobaccoinstitute.com, Bates No. TIMN0034730/4731, downloaded 2 July 1999

14 Sparber and Associates, Inc. "Draft Insurance Program", August 1990. Tobacco Institute. www.tobaccoinsitute.com, Bates No. TIMN385398/5425, downloaded 30 June 1999 .
15 Hrycal C, Rinker M. “Subject: Insurance Program”, memorandum from to Susan Stuntz, 25 October 1991. Tobacco Institute. www tobaccoinstitute com, Bates No. TIMN385689, downloaded 1 June 1999

16 Anon. "We support; we oppose; we do not". List, no date. Tobacco Institute. www.tobaccoinstitute.com, Bates No. TIMN0140787. downloaded 26 February 2000.

17 Glantz S, Slade J, Bero L, Hanauer P, Barnes D. The Cigarette Papers, 1996, University of California Press, p 355
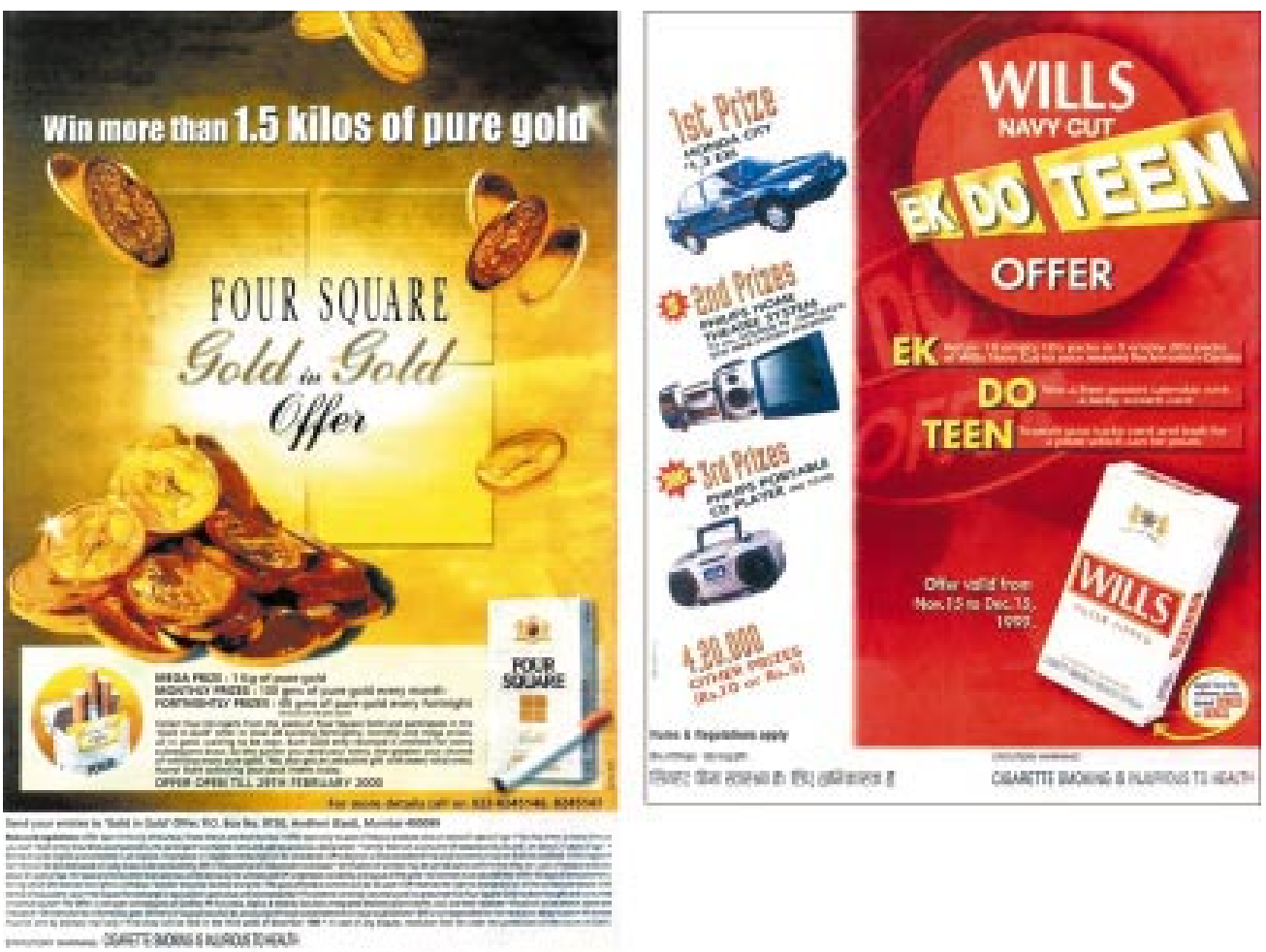

Residents of Mumbai (Bombay) in India, a nation with GNP per capita of $\$ 670$ (cf UK $£ 20,870$ ) and where $30 \%$ of the population will not survive to the age of 60, are currently benefitting from the marketing genius of local tobacco company brand wars offering a kilo of gold or a Honda car. Four pack coupons gets you one entry in the Four Square lottery, and five empty Wills packs gets you a ticket for the Honda. Enter as many times as you like! Remember, tobacco advertising doesn't encourage increased consumption .... 